JST 8(1)(2019)
JURNAL SENI TARI
Terakreditasi SINTA 5

\title{
Fenomena Cross Gender Pertunjukan Lengger pada Paguyuban Rumah Lengger
}

\author{
Rindik Mahfuri ${ }^{1}$, Moh. Hasan Bisri ${ }^{2}$ \\ Jurusan Pendidikan Sendratasik, Fakultas Bahasa dan Seni, Universitas Negeri \\ Semarang, Indonesia
}

\section{Info Artikel \\ Sejarah Artikel \\ Diterima : 23 Mei 2019 \\ Disetujui : 22 Juni 2019 \\ Dipublikasikan :23 Juli \\ 2019}

\section{Keywords:}

cross gender; lengger;

performance

\begin{abstract}
Abstrak
Cross gender merupakan suatu istilah peran atau sifat yang menyeberang dari kepribadian seseorang. Fenomena cross gender yang terjadi adalah munculnya kembali penari lengger laki-laki pada kesenian Lengger yang sudah hampir hilang karena perkembangan zaman tepatnya di Paguyuban Rumah Lengger di Desa Pandak Kecamatan Baturaden Kabupaten Banyumas. Penelitian ini bertujuan untuk mengetahui fenomena bentuk pertunjukan kesenian Lengger Paguyuban Rumah Lengger yang ditarikan oleh penari cross gender dan fenomena penari cross gender dalam pertunjukan kesenian Lengger di Paguyuban Rumah Lengger. Metode penelitian yang digunakan adalah metode penelitian kualitatif. Pengumpulan data dalam penelitian ini menggunakan metode observasi, wawancara dan dokumentasi. Teknik analisa data menggunakan reduksi data, penyajian data, dan penarikan kesimpulan. Teknik keabsahan data menggunakan triangulasi sumber. Berdasarkan hasil analisis data, hasil temuan dari fenomena cross gender pada kesenian Lengger paguyuban Rumah Lengger meliputi fenomena bentuk pertunjukan yang terdiri dari struktur pertunjukan (yang meliputi pola awal, pola tengah, dan pola akhir pertunjukan), gerak, properti, tata rias dan tata busana, musik iringan, dan tempat pertunjukan, serta fenomena penari cross gender dalam pertunjukan Lengger yang dapat ditunjukkan dari segi gerak dan tata rias busana.

Abstract

Cross gender is a term of the role or trait that crosses his personality. The phenomenon of cross gender that occurred is the re-emergence of male lengger dancers in Lengger that had almost extinct due to modernity precisely in the Paguyuban Rumah Lengger in the Pandak Village, Baturaden District. This research purposed to determine the phenomenon of Paguyuban Rumah Lengger art performances performed by cross gender dancers and the presence of them in Lengger. This research used a qualitative methodology. The data collections in this study used observation, interviews, and documentation. Teknik data using reduction data, presentation of data, and verification. Engineering the validity of data using triangulation source. Based on the results of data analysis, the findings of cross gender phenomena in Lengger art of the Paguyuban Rumah Lengger included the form of performances phenomenon consisting of performance structures (which included initial patterns, middle patterns, and final patterns of performances), motion, property, make up and costume, accompaniment music, and venue.
\end{abstract}

\footnotetext{
$\triangle$ Alamat korespondensi:

Gedung B2 Lantai 1 FBS UNNES

Kampus Sekaran, Gunungpati, Semarang 50229

Email : 1.rindhikmahfuri@gmail.com

2.hasanbisriunnes@mail.ac.id
} 


\section{PENDAHULUAN}

Cross gender merupakan suatu istilah peran atau sifat yang menyeberang dari kepribadiannya. Istilah ini ditujukan salah satunya untuk penari yang memiliki kepribadian seorang laki-laki yang sewaktuwaktu dapat berpenampilan sebagai seorang perempuan dalam suatu pertunjukan begitupula sebaliknya.

Paguyuban Rumah Lengger atau yang sekarang lebih dikenal dengan nama Lengger Lanang Langgeng Sari, berdiri pada tanggal 11 September 2013 di Desa Pandak Kecamatan Baturaden. Paguyuban Rumah Lengger merupakan salah satu paguyuban yang masih mempertahankan penari cross gender atau lengger lanang dalam setiap pementasan Lengger. Paguyuban ini dipimpin oleh seorang seniman Lengger Banyumasan yang bernama Tora Dinata, beliau juga adalah salah satu penari cross gender.

Penelitian terkait tentang fenomena cross gender telah dilakukan oleh Muh. Muchibbur Rochman dan V. Indah Sri Pinasti, UNY yang termuat dalam Jurnal Pendidikan Sosiologi 2015 dengan judul Fenomena CrossGender Dalam Raminten 3 Cabaret Show, Mirota Batik. Tujuan penelitian ini adalah untuk mengetahui bentuk kebebasan berekspresi seni pertunjukan di Yogyakarta sebagai salah satu seni genre baru. Kedua, untuk mengetahui ekspresi estetis para penari Cabaret Show secara personal. Ketiga, untuk mengetahui relasi ekspresi estetis yang ditimbulkan atas peran para penari cross gender di atas panggung Cabaret Show. Keterkaitan dengan penelitian ini adalah membahas tentang fenomena cross gender, akan tetapi terdapat perbeaan pada hasil. Penelitian Muh. Muchibbur Rochman dan V. Indah Sri Pinasti tidak membahas tentang bentuk pertunjukan, sedangkan penelitian ini membahas tentang bentuk pertunjukan.

Penelitian yang dijadikan sebagai referensi kedua adalah penelitian Muriah Budiarti yang termuat dalam Jurnal Harmonia Vol. 4 No. 2 Tahun 2003 yang berjudul Mengubah Citra Lengger Menjadi Media Ekspresi Estetis Penelitian ini membahas bahwa keberadaan kesenian lengger pada masa lalu identik dengan praktek-praktek prostitusi terelubung, dan sekarang berubah menjadi media ekspresi estetis.

Penelitian yang dijadikan sebagai referensi ketiga adalah penelitian dari Hasan Bisri 2010 yang berjudul Gender Koreografer Wanita Dalam Karya Tari. Hasan Bisri dalam penelitiannya menyimpulkan bahwa konstruksi peran laki-laki dan perempuan dalam proses karya tari terjadi pada lingkungan sosial keluarga dan lingkungan sosial masyarakat.

Munculnya kembali penari cross gender pada kesenian Lengger dan persepsi masyarakat yang berbeda-beda mengenai penari cross gender, maka peneliti tertarik untuk mengkaji penelitian tentang Fenomena Cross Gender Pertunjukan Lengger Pada Paguyuban Rumah Lengger Di Masyarakat Desa Pandak Kecamatan Baturaden Kabupaten Banyumas.

Tujuan dari penelitian ini adalah untuk mengetahui bagaimana bentuk pertunjukan Lengger yang ditarikan oleh cross gender di Paguyuban Rumah Lengger dan bagaimana peran penari cross gender dalam pertunjukan lengger di Paguyuban Rumah Lengger.

Permasalahan yang mendasari peneliti adalah Bagaimana Fenomena Cross Gender Pertunjukan Lengger Pada Kesenian Lengger Paguyuban Rumah Lengger dengan kajian pokok sebagai berikut: (1) Bagaimana bentuk pertunjukan Lengger yang ditarikan oleh Cross Gender di Paguyuban Rumah Lengger? (2) Bagaimana fenomena penari Cross Gender dalam pertunjukan lengger di Paguyuban Rumah Lengger?

Cross gender terdiri dari dua kata yang berasal dari Bahasa Inggris yaitu, cross yang berarti silang atau penyilangan dan kata gender yang berarti jenis kelamin. Jadi cross gender adalah seseorang yang melakukan silang peran, baik itu yang dilakukan anak laki-laki, maupun anak perempuan, bukan orang yang bersilang atau bertukar jenis kelamin. Cross gender merupakan bagian dari transgender. Cross gender disini adalah persilangan pemeranan karakter atau bisa juga disebut silang gender seperti karakter perempuan diperankan oleh laki-laki atau karakter laki-laki diperankan oleh perempuan. Biasanya istilah cross gender ini di gunakan dalam pertunjukan seni seperti tari dan wayang. Menurut Wayan Dibia dalam Didik Nini Thowok (2005:ix) fenomena penari cross gender ini mengakar pada kesenian Bali kuno, dimana ada drama tari yang karakter perempuannya diperankan oleh laki-laki yaitu Arja Muani. Seni tari sebagai ekspresi perasaan manusia yang bersifat estetis, yang diungkapkan melalui gerak tubuh yang ritmis dan indah. Seni tari dijadikan sarana komunikasi untuk menyampaikan pesan dari penari kepada penonton. Kesimpulan yang dapat diambil dari penjelasan diatas adalah bahwa penari cross gender adalah seseorang yang melakukan persilangan peran atau karakter dalam seni pertunjukan, tetapi tidak melakukan pergantian 
jenis kelamin atau yang sering disebut dengan operasi jenis kelamin. Mereka hanya berdandan dan memakai atribut layaknya perempuan pada saat pertunjukan.

PenuturanWidyastutieningrum (2012:3) Pengelompokan kualitas tari di Jawa terbagi menjadi tiga kelompok yaitu tari putri, tari putra alus, dan tari putra gagah. Pembedaan kualitas tari putri, putra alus, dan putra gagah itu sangat ditentukan oleh ciri-ciri gerak yang menyertainya, seperti pada volume gerak lengan. Kualitas tari putri, volume gerak lengan yang dilakukan kurang lebih 22,5 derajat, sementara tari kualitas alus volume gerak lengan yang dilakukan kira-kira 45 derajat, sedangkan tari kualitas gagah volume gerak lengan yang dilakukan kira-kira 90 derajat. Pembeda berikutnya yaitu terletak pada bentuk adeg, jarak langkah kaki pada lumaksana, bentuk gerak tubuh leyekan, dan tinggi rendahnya pandangan mata, juga tempo gerak, di samping itu rasa gerak (rasa tari) atau ungkapan pengalaman batin yang disampaikan (Widyastutieningrum 2012:3).

Bentuk dalam Kamus Besar Bahasa Indonesia diartikan sebagai wujud, rupa (Suharso 2015:84). Wujud terdiri dari dua macam yaitu wujud yang nyata dan abstrak. Wujud nyata merupakan wujud yang dapat dilihat dengan mata secara langsung. Sedangkan wujud yang abstrak merupakan wujud yang tidak bisa dilihat dengan indera penglihatan tetapi dapat di dengar dengan indera pendengaran, misalnya musik, dan suara. Penuturan Jazuli (2016:12) tari memiliki bentuk yang terlihat antara lain gerak, bagian tubuh yang meliputi kepala, tangan, dan kaki, jumlah penari, kelengkapan sajian yang terdiri dari tema, musik/iringan, tata rias, tata busana, tata cahaya, tata suara, tempat, dan property), tingkat energi (banyak-sedikit, keras-lembut, kuat-lemah), dan tempo (teba, irama, ritme).

Sunaryadi (2000:4) menyatakan bahwa pada tahun 1918 penari Lengger adalah laki-laki yang berpakaian wanita. Kesenian Lengger atau Lenggeran merupakan kesenian yang tumbuh dan berkembang di wilayah Banyumas sejak tahun 1755 di daerah Jatilawang Kabupaten Banyumas dan kemudian menyebar di daerah Kalibagor Kabupaten Banyumas. Bagi masyarakat Banyumas, Lengger merupakan serpihan tradisi yang tidak dapat ditinggalkan begitu saja karena telah dianggap sebagai ciri khas daerah tersebut (Sunaryadi 2000:6). Di sisi lain dalam pertunjukan rakyat, berbagai kepercayaan pra-Hindu yang magis-religius masih tetap merupakan unsur yang dominan, seperti pada pementasan kesenian Lengger Banyumasan sebelum acara dimulai, terlebih dahulu melakukan ritual sesaji dengan menyalakan dupa untuk kelancaran dalam pementasannya.

\section{METODE}

Penelitian yang berjudul Fenomena Cross Gender Pertunjukan Lengger pada Paguyuban Rumah Lengger menggunakan metode kualitatif. Pendekatan yang digunakan dalam penelitian ini adalah pendekatan deskriptif kualitatif. Pendekatan desriptif kualitatif merupakan prosedur penelitian yang menghasilkan data deskriptif berupa kata-kata tertulis atau lisan dari orang-orang dan perilaku yang dapat diamati (Moleong 2001:3). Disebut metode kualitatif karena data penelitian berupa deskripsi-deskripsi dalam bentuk tulisan. Deskriptif dalam penelitian dilakukan untuk menyelidiki keadaan atau kondisi sehingga mendapatkan data, kemudian data yang terkumpul dianalisis dan hasilnya dipaparkan dalam bentuk laporan penelitian yang bertujuan untuk menjelaskan sesuai dengan keadaannya. Data yang dikumpulkan berupa kata-kata, gambar dan bukan angka-angka (Moleong 2001:6). Data yang yg dikumpulkan berupa deskripsi-deskripsi atau uraian kata tentang bentuk pertunjukan yang meliputi elemenelemen pertunjukan yang terdapat pada Paguyuban Rumah Lengger seperti gerak, tata rias busana, musik/iringan, property, dan tempat pertunjukan.

Lokasi penelitian ini berada di Paguyuban Rumah Lengger yang terletak di Desa Pandak, Rt 03 Rw 04 Kecamatan Baturaden, Kabupaten Banyumas. Teknik pengumpulan data menggunakan teknik wawancara, observasi, dan dokumentasi. Teknik analisis data menggunakan reduksi data, penyajian data, dan penarikan kesimpulan. Teknik keabsahan data menggunakan triangulasi sumber untuk memeriksa.

Wawancara dilakukan untuk menggali data yang berkaitan dengan fenomena cross gender pertunjukan Lengger pada Paguyuban Rumah Lengger, peneliti melakukan wawancara secara langsung yang terstruktur kepada beberapa narasumber.

Narasumber tersebut diantarnya Tora Dinata selaku ketua paguyuban Lengger dan penari Lengger di Paguyuban Rumah Lengger. Hasil wawancara memberikan penjelasan 
mengenai sejarah berdirinya Paguyuban Rumah Lengger dan keberadaan penari cross gender di masyarakat, mengenai proses penciptaan gerak Lenggeran, bentuk pertunjukan Lengger secara keseluruhan dari aspek pokok gerak sampai aspek pendukung berupa rias, busana, pelaku, tempat pertunjukan. Proses latihan Lengger hingga persiapan dalam pertunjukan Lengger serta keunikan yang terdapat dalam pertunjukan Lengger Paguyuban Rumah Lengger yang membuat pertunjukan Lengger menarik sehingga penonton mampu menikmati pertunjukan, dan data mengenai peran penari cross gender pada pertunjukan Lengger Paguyuban Rumah Lengger. Bapak Sukendar Hadi Soemarto selaku pemain kendhang atau pemusik Paguyuban Rumah Lengger, menghasilkan data mengenai sejerah dari kesenian Lengger, pola garap iringan pertunjukan Lengger Paguyuban Rumah Lengger, dan alat musik yang digunakan. Otniel Tasman selaku seniman Lengger Banyumasn, menghasilkan data mengenai ururtan sajian pertunjukan pada kesenian Lengger Banyumasan.

Observasi dilakukan pada tanggal 17 Mei 2018 di tempat latihan di Desa Karangtengah Baturaden. Memperoleh data mengenai sejarah berdirinya Paguyuban Rumah Lengger dan keberadaan penari cross gender di masyaraka. Tanggal 20 Desember 2018 dilakukan di tempat latihan yaitu di Desa Karangtengah Baturaden. Hasil observasi memperoleh data mengenai proses penciptaan gerak tari Lenggeran, bentuk pertunjukan Lengger secara keseluruhan dari aspek pokok gerak sampai aspek pendukung berupa rias, busana, tempat pertunjukan. Proses latihan Lengger hingga persiapan dalam pertunjukan Lengger. Dilanjutkan tanggal 21 Desember 2019 di kediaman bapak Sukendar selaku pemusik. Hasil observasi memberikan penejelasan mengenai alat musik dan iringan yang digunakan dalam pertunjukan Lengger Paguyuban Rumah Lengger. Observasi selanjutnya dilakukan pada tanggal 15 Januari 2019 di rumah Ibu Rohini selaku penikmat pertunjukan Lengger Paguyuban Rumah Lengger di Jl. Yudhistira RT 04 RW 04 Pandak Baturaden dalam acara pernikahan (Esti dan Toni). Hasil observasi memperoleh data mengenai bentuk pertunjukan Lengger Paguyuban Rumah Lengger serta untuk memperoleh dokumentasi pertunjukan Lengger Paguyuban Rumah Lengger. Observasi pada tanggal 2 Februari 2019 dilakukan di gedung Gubernuran Kota Semarang. Hasil observasi memperoleh data mengenai peran penari cross gender dan bagaimana mereka menyiasati tubuh penari cross gender agar terlihat seperti perempuan.

\section{HASIL DAN PEMBAHASAN}

Hasil penelitian dan pembahasan dalam penelitian ini meliputi gambaran umum Paguyuban Rumah Lengger, fenomena bentuk pertunjukan lengger cross gender, dan peran penari cross gender dalam pertunjukan lengger.

\section{Paguyuban Rumah Lengger}

Paguyuban Rumah Lengger terletak di J1. Yudistira, Dusun II Pandak, kecamatan Baturaden, kabupaten Banyumas. Paguyuban Rumah Lengger yang diketuai oleh Tora Dinata berdiri pada tanggal 11 September 2013, kemudian pada tanggal 29 September 2016 berganti nama menjadi Lengger Lanang Langgeng Sari, dengan anggota penari hingga saat ini berjumlah 6 orang dari berbagai daerah disekitar Banyumas yang meliputi: Tora Dinata (Baturaden), Sigit Kurniawan (Baturaden), Didit Suryanto (Baturaden), Ryan Nurgia Nova (Gombong Kebumen), Piko Prasetyo (Banyumas), dan Wahyudi Rismansyah (Banjarnegara).

\section{Bentuk Perntunjukan Lengger}

Tora Dinata menuturkan bahwa kesenian Lengger biasa ditarikan pada saat acara hiburan, seperti penyambutan tamu yang datang ke daerah Banyumas, acara hiburan di pernikahan, acara hiburan untuk kegiatan pariwisata, dan acara-acara lain yang ada hubungannya dengan kegiatan pariwisata dan kebudayaan banyumas. (Wawancara 20 Desember 2018)

Sebuah bentuk pertunjukan tentu tidak terlepas dari elemen-elemen yang mendasari pertunjukan tersebut. Elemen-elemen yang terdapat dalam uraian fenomena bentuk pertunjukan Lengger di Paguyuban Rumah Lengger (Lengger Lanang Langgeng Sari) terdiri dari struktur pertunjukan (pola awal, tengah, dan akhir), gerak, tata rias dan busana, musik iringan, properti, dan tempat pertunjukan.

\section{Struktur Pertunjukan}

Paguyuban Rumah Lengger atau yang sekarang disebut Lengger Lanang Langgeng Sari memiliki pola garap kesenian Lengger yang berdeda dari bentuk pertunjukan yang lain, dikarenakan menggabungkan unsur gerak putri dan putra gagah dalam setiap pertunjukannya. 
Lengger Lanang Langgeng Sari adalah salah satu paguyuban yang melestarikan kesenian Lengger dengan menggunakan beberapa ragam gerak khas Lengger Banyumas yang sudah dikembangkan lagi pola geraknya. Ragam gerak tersebut meliputi cuthatan sampur, penthangan asta, entrakan, geol, dan gerak penghubung keweran dan sindeht. Struktur pertunjukannya dibagi menjadi tiga pola (pola awal, pola tengah, pola akhir).

Didit Suryanto sebagain salah satu penari Lengger pada Paguyuban Rumah Lengger menuturkan bahwa pada bagian pola garap awal dalam pertunjukan Lengger Lanang Langgeng Sari memunculkan unsur gerak gagah yaitu dengan melakukan gerak yang menggambarkan ritual sebelum menjadi Lengger dengan berdandan layaknya seorang penari laki-laki sambil membawa nampan yang berisikan sanggul dan sampur dengan diiringi Tembang Mantram. (Wawancara 15 Januari 2019). Setelah melakukan penggambaran ritual Lengger, penari laki-laki memakai sanggul dan aksesoris lain lalu berpakaian seperti layaknya seorang penari Lengger dan disinilah babak awal pertunjukan Lengger Lanang Langgeng Sari dimulai dengan diiringi gendhing sekar gadhung. Tiap pergantian antara bagian satu ke bagian selanjutnya ditandai dengan gerak sindhet. Sindhet merupakan salah satu gerak penghubung pada tari gaya Banyumasan. Pada bagian awal biasanya seluruh ragam gerak pokok ditampilkan terlebih dahulu, lalu gerakan tersebut dikembangkan lagi sesuai dengan susunan yang sudah disepakati oleh para penari. Pola tengah dalam pertunjukan Lengger Lanang Langgeng Sari, penari Lenger menari dengan diiringi gendhing-gendhing Banyumasan seperti Lobong Ilang, Gunungsari Kalibagora, Ngerong dan Sulang Surup, terkadang juga diselingi dengan sajian campursarian. Pola akhir pertunjukan Lengger Lanang Langgeng Sari, penari Lengger menari lagi dengan diiringi gendhing Eling-Eling maupun Bendrong Kulon yang menandakan akan berakhirnya pertunjukan Lengger Lanang Langgeng Sari.

\section{Gerak}

Paguyuban Rumah Lengger (Lengger Lanang Langgeng Sari) dalam setiap pertunjukannya, menggunakan beberapa ragam gerak gaya banyumasan dan juga desain lantai untuk menambah kesan estetis dalam sajian pertunjukan Lengger. Wahyudi Rismansyah menuturkan bahwa ragam gerak tari gaya Banyumasan tersebut meliputi cuthatan sampur, penthangan asta, entrakan, jalan lembeyan, geol, dan gerak penghubung keweran dan sindhet, yang kemudian gerakan itu kembangkan lagi oleh penari Lengger Lanang Langgeng Sari. (Wawancara 21 Desember 2018)

Desan laintai atau yang sering kita sebut pola lantai adalah salah satu elemen penting dalam perturunjukan. Fungsi pola lantai yaitu untuk menambah daya tarik sebuah pertunjukan salah satunya adalah pertunjukan Lengger Lanang Langgeng Sari. Pola lantai utama yang biasa digunakan meliputi Lingkaran, zig-zag, huruf $\mathrm{V}$, dan horisontal.

\section{Rias Busana}

Ryan Nurgia Nova menuturkan bahwa rias yang digunakan dalam pertunjukan Lengger Lanang Langgeng Sari adalah rias korektif (Wawancara 20 Desember 2018). Rias korektif adalah suatu bentuk tata rias yang bersifat menyempurnakan (koreksi). Tata rias ini bertujuan untuk menyembunyikan kekurangan-kekurangan yang ada pada wajah dan menonjolkan hal-hal yang menarik dari wajah penari Lengger Lanang Langgeng Sari yang dapat memeberikan kesan cantik. Kesan cantik yang ditimbulkan dari tata rias korektif sering membuat orang terpesona ketika melihat penari Lengger Lanang Langgeng Sari, bahkan ada yang menganggap bahwa mereka cantik seperti perempuan pada umumnya.

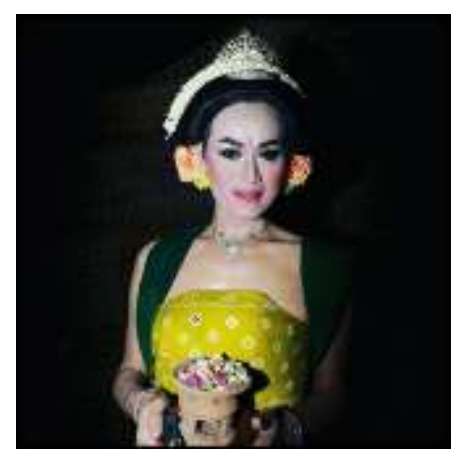

Gambar 1. Rias Korektif Lengger Lanang Langgeng Sari

(Foto : Tora Dinata, 2018)

Busana merupakan salah satu unsur pendukung dalam sebuah pertunjukan Lengger. Fungsi tata busana tari ini adalah sebagai pelindung tubuh, Memperindah penampilan, Memperjelas karakter yang dibawakan atau memperkuat ekspresi gerak. Didit Suryanto selaku penari dan penata busana Lenger Lanang Langgeng Sari menjelaskan bahwa busana yang digunakan oleh penari Lengger 
Langgeng Sari meliputi kain jarit yang digunakan untuk menutupi tubuh bagian pinggul hingga kaki, mekak untuk menutupi tubuh bagian dada hingga pinggul, untuk aksesoris yang digunakan oleh penari Lengger Lanang Langgeng Sari meliputi sanggul, sirkam, menthul, gunungan, hiasan bunga, giwang, kalung, gelang, dan sampur (Wawancara tanggal 20 Desember 2018).

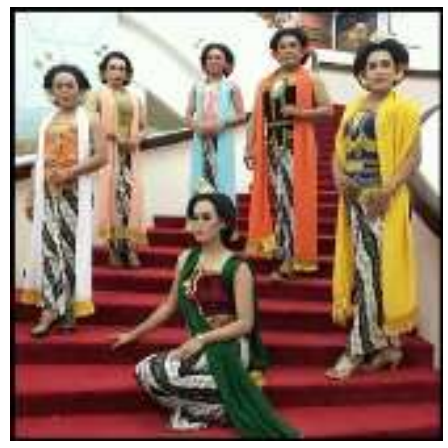

Gambar 2. Busana Penari Lengger Lanang

(Foot : Paguyuban Rumah Lengger Lanang

Langgeng Sari, Februari 2019)

Busana yang digunakan oleh penari Lengger Lanang Langgeng Sari meliputi jarit, stagen, mekak bludru, mekak bludru, Ilat-ilatan, Sampur Sifon, Sabuk, gelang, hiasan bunga, menthul, sirkam, gunungan, kalung, giwang, dan sanggul.

Jarit adalah kain bermotif batik berbentuk segi panjang yang mempunyai ukuran $3 \times 1,5$ meter. Jarit berfungsi sebagai penutup tubuh bagian bawah. Penggunaan jarit dengan cara dililitkan pada tubuh kemudian bagian tepinya disisakan untuk diwiru pada kaki bagian kiri maupun diwiru kecil biasa. Kain jarit yang digunakan biasanya menggunakan motif parang.

Stagen adalah kain bentuk persegi panjang dengan ukuran panjang \pm 3 meter yang diguanakan untuk melekatkan jarit agar tidak mudah lepas dan kencang. Penggunaannya setelah memakai jarit dengan cara dililitkan ke tubuh secara kencang agar tidak mudah lepas.

Mekak bludru adalah kain bludru yang dijahit dengan bentuk persegi yang dihiasi dengan mote kecil-kecil ataupun benang berwarna emas. Penggunaannya setelah memakai jarit dan stagen, dikaitkan kancingnya. Alasan penata busana memilih kain bludru untuk busana penari Lengger dikarenakan ingin memberikan kesan anggun dan elegan pada penari Lengger Lanang Langgeng Sari.

Ilat-ilatan merupakan kain yang berbentuk layang-layang ataupun persegi panjang dengan lebar sekitar $15 \mathrm{~cm}$ pada bagian atas dan $10 \mathrm{~cm}$ pada bagian bawah, yang dihiasi mote dan benang emas pada setiap tepi. Penggunaannya setelah memakai mekak, ilatilatan dipasang pada bagian dada. Penata busana menggunakan ilat-ilatan dikarenakan untuk menutup sisa mekak yang berlebih dan kurang rapi pada badan bagian depan.

Sampur Sifon adalah kain sifon lembut bentuk persegi panjang $250 \mathrm{~cm}$ sampai $300 \mathrm{~cm}$, berhiaskan mote emas pada ujung sampur yang digunakan untuk property menari. Penggunaanya setelah memakai mekak bludru dengan cara dikalungkan ke leher. Penata busana memilih kain sifon yang lembut dengan diberi sentuhan mote emas pada ujung sampur, bertujuan agar penari lebih mudah menggerakan sampur untuk di ragam gerak cuthatan sampur maupun seblak samput. Warna sampur yang biasa digunakan dalam pertunjukan Lenger Lanang Langgeng Sari adalah putih, merah, hijau, kuning, biru, dan pink.

Sabuk adalah alat yang berbahan bludru dan dihiasi mote dan benang emas di sepanjang tepinya, dengan bulatan berbahan perunggu sebagai pengkaitnya. Penggunaannya setelah memakai mekak dan ilat-ilatan, kemudian sabuk dililitkan ke pinggang kemudian dikaitkan. Tujuan penggunaan sampur untuk memberikan kesan anggun dan busana terlihat rapi ketika busana dipakai penari Lengger Langgeng Sari.

Gelang tangan adalah perhiasan yang terbuat dari perunggu, kuningan dan sebagainya, yang dihiasi dengan berlian-berlian yang berkilau, digunakan untuk menghiasi pergelangan tangan. Penggunaannya setelah semua kostum dikenakan. Tujuan penari Lengger Langgeng Sari menggunakan gelang tangan, agar penari terlihat lebih terlihat elegan.

Hiasan bunga adalah bunga imitasi yang digunakan untuk menghiasi rambut setelah sanggul dipasang. Dipasangkan dengan menggunakan cepet biting. Tujuan penari Lengger Langgeng Sari menggunakan hiasan bunga untuk memberikan kesan penari terlihat lebih cantik, anggun, dan elegan.

Menthul adalah perhiasan berbentuk seperti bunga yang terbuat dari besi yang dicat warna emas dan dihiasi dengan berlian pada bagian bunga. Penggunaanya setelah menggunakan sanggul, dipasang atas sanggul dengan cara ditusukan ke dalam sanggul setelah menggunakan menthul. Tujuan penari Lengger Langgeng Sari menggunakan menthul untuk memberikan kesan penari terlihat lebih cantik, anggun, dan elegan. 
Sirkam merupakan hiasan berbentuk setengah lingkaran yang terbuat dari besi dicat emas dan dihiasi permata. Penggunaannya setelah memakai sanggul, dipasang pada bagian kepala tepatnya diatas ubun-ubun. Tujuan penari Lengger Langgeng Sari menggunakan sirkam untuk memberikan kesan penari terlihat lebih cantik, anggun, dan elegan.

Gunungan merupakan hiasan kepala yang terbuat dari besi berbentuk gunungan berwarna emas dan dan diberi mote berlian yang dipasang di atas kepala setelah menggunakan sanggul. Penggunaannya dengan cara ditusukkan pada sanggul bagian atas sebelum menggunakan menthul. Tujuan penari menggunakan gunungan untuk memberikan kesan penari terlihat lebih cantik, anggun, dan elegan.

Kalung adalah perhiasan berbentuk tiga tingkatan bulan sabit yang terbuat dari perunggu, kuningan dan sebagainya, yang dihiasi dengan berlian-berlian yang berkilau, digunakan untuk menghiasi pergelangan tangan. Penggunaannya setelah semua kostum dikenakan.

Giwang adalah perhiasan yang terbuat dari perunggu, kuningan dan sebagainya, yang dihiasi dengan berlian-berlian yang berkilau dan mote berwarna keemasan yang panjang, digunakan untuk menghiasi kedua telinga. Penggunaannya setelah semua kostum dikenakan dengan cara dikaitkan pada telinga.

Sanggul adalah rambut imitasi yang digunakan setelah rambut di hair spray dan di jepit biting dan dikenakan dengan cara dijepit dengan hairnal.

\section{Properti}

Properti merupakan suatu bentuk peralatan penunjang gerak sebagai wujud ekspresi dalam pertunjukan tari Lengger yang mempunyai daya tarik tersendiri untuk memikat penonton. Salah satu jenis properti yang digunakan dalam pertunjukan Lengger adalah dance property yang berupa ebeg, dan tampah.

Penggunaan ebeg sebagai properti pada pertunjukan Lengger Lanang Langgeng Sari, sesuai dengan urutan sajian pertunjukan yaitu pada babak ebeg-ebegan, sedangkan penggunaan properti tampah digunakan oleh penari untuk membawa aksesoris penari Lengger yang terdiri dari sanggul pasangan dan sampur untuk dipakai di atas panggung, terkadang juga tampah diisi dengan sesaji, isi tampah bisa berbeda-beda tergantung dengan konsep yang akan digarap oleh penari.

\section{Musik Iringan}

Bapak Sukendar Hadi Soemarto selaku pemusik menuturkan bahwa iringan atau musik juga sangat berperan dalam setiap pertunjukan kesenian Lengger sebagai pengiring tari maupun penambah suasana supaya pertunjukan kesenian Lengger menjadi ramai atau gayeng. Alat musik iringan yang digunakan yaitu seperangkat alat musik calung yang terdiri dari gambang, dhendhem, kenong, gong, dan kendang ciblon. (Wawancara 21 Desember 2018)

Gambang terbuat dari bambu wulung (bambu ungu) yang terdiri dari gambang barung dan gambang penerus. Gambang barung dan gambang penerus adalah dua alat musik yang bila dilihat dari bentuk, ukuran, maupun sistem pelarasannya tidak ada yang berbeda. Yang membedakan keduanya adalah teknik permainannya. Cara memainkan gambang sama dengan memukul balugan pada gamelan Jawa, akan tetapi gambang dimainkan dengan menggunakan kedua tangan secara bersamaan.

Alat musik calung ini berlaraskan slendro yaitu gambang barung berfugsi sebagai pembuka dan sebagai melodi dalam gending, sedangkan gambang penerus berfungsi sebagai imbal yang mengikuti gambang barung. Tabuh gambang terbuat dari batang besi dan ujung tabuh terbuat dari kayu yang diberi karet pada pinggiran kayu, sehingga ketika dipukul mudah bergetar dan menghasilkan suara yang lebih nyaring.

Wilahan pada gambang berjumlah 16 wilahan yag berawal dari:

$\begin{array}{lccccccc}3 & 5 & 6 & 1 & 2 & 3 & 5 & 6 \\ (l u) & (\text { mo }) & (\text { nem }) & (j i) & (\text { ro }) & (l u) & (\text { mo }) & (\text { nem }) \\ 1 & 2 & 3 & 5 & 6 & \dot{1} & \dot{2} & \dot{3} \\ (j i) & (\text { ro }) & (l u) & (\text { mo }) & (\text { nem }) & (j i) & (\text { ro }) & (l u)\end{array}$

Kenong merupakan alat musik tradisional khas Banyumas yang berjumlah enam wilahan yang terdiri dari. nada 2 (ro), 3 (lu), 5 (mo), 6 (nem), 1 (ji), $\dot{2}$ (ro). Kenong dalam gamelan calung Banyumasan tidak jauh berbeda tehnik permainannya dengan kenong pada gamelan Jawa. Kenong berawal dari nada rendah 2 (ro), yang berfungsi sebagai kethuk yang di pukul menggunakan tangan kiri, sedangkan nada yang lainnya di tabuh dengan memnggunakan tangan kanan. Tabuh kenong sama dengan tabuh pada gambang dengan batang yang terbuat dari besi besi dan ujung tabuh terbuat dari kayu yang diberi karet pada pinggiran kayu, sehingga ketika dipukulkan 
mudah bergetar sehingga suara yang dihasilkan akan lebih nyaring.

Dendhem merupakan alat musik tradisional khas Banyumas yang berjumlah enam wilahan dengan ukuran sedikit lebih besar dari ukuran wilahan pada gambang dan kenong. Penataan wilahan pada dendhem sama dengan penataan wilahan pada kenong yang terdiri dari nada $2(\mathrm{ro}), 3(\mathrm{lu}), 5(\mathrm{mo}), 6(\mathrm{nem})$, i

(ji), $\dot{2}$ (ro). Nada pada dendhem lebih rendah dari nada kenong. Teknik permainan pola pada dendhem sama seperti halnya teknik permainan bonang penerus pada gamelan jawa. Tabuh yang digunakan sedikit berbeda dengan tabuh gambang dan kenong.

Tabuh dendhem juga lebih besar dari tabuh kenong dan gambang agar selaras dengan wilahannya. Tabuh dendhem terbuat dari batang kayu dan ujung tabuh terbuat dari kayu yang diberi karet pada pinggiran kayu sehingga jika digunakan untuk memukul akan lebih kuat dengan menghasilkan suara yang intensitasnya besar.

Gong Bumbung merupakan bagian dari gamelan calung yang bentuknya sedikit unik dari gamelan calung yang lainnya. Gong sebul atau gong bumbung ini terbuat dari dua buah bambu yang berbeda ukuran diameternya. Bambu yang berukuran besar berfungsi sebagai lubang resonansi sedangkan bambu yang kecil berfungsi sebagai alat sebul atau tiup. Teknik memainkannya dengan cara menggetarkan bibir layaknya meniup terompet. Nada yang di hasilkan merupakan produksi suara dari mulut kita sendiri. Gong bumbung ini fungsinya sama seperti gong pada gamelan jawa.

Kendhang merupakan alat musik yang terbuat dari kayu yang dilubangi pada bagian tengah kayu dan padasetiap ujung lubang ditutup menggunakan kulit hewan. Cara memainkannya dengan dipukul menggunakan kedua tangan pada bagian kanan dan bagian kiri dengan mengikuti tehnik gaya Banyumasan yang sedikit rancak dan penuh semangat, sedangkan gambar merupakan ketipung sebagai pelengkap yang selalu ada untuk mengiringi dalam kesenian Lengger Banyumasan.

Bapak Sukendar Hadi Soemarto selaku pemusik kesenian Lengger Paguyuban Rumah Lengger, menuturkan bahwa Iringan yang biasa digunakan alam pertunjukan Lengger Lanang Langgeng Sari adalah Tembang Mantram, Gendhing Sekar Gadung, Lobong Ilang, ElingEling Banyumasan, Gunungsari Kalibagoran. (Wawancara 21 Desember 2018)

Pola Awal Notasi

Tembang Mantram

$\left[\begin{array}{llllllllllllll}\ldots & 2 & 2 & \overline{13} & 3 & 0 & 5 & 5 & 2 & \overline{32} & 3\end{array}\right.$

De- wa-ta-sa ja-gat ja-gat u- rip

•.. 356 i 6 i $\overline{\dot{2} i 6} \overline{i 6} \quad 3 \quad \overline{23} \overline{33}$

Roh- ma- nung- sa mle- bu ang- ga ni- ra- kudo i

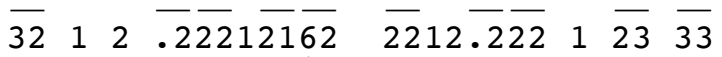
wakkabir i- wakkabir ra-na i-wak kabir iwak kabir ra- na $\mathrm{i}$

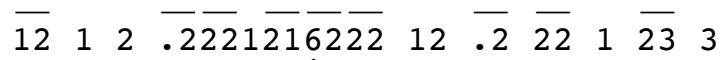

wakkabir i-wakkabir ra-na i-wak kabir iwak kabir ra- $\mathrm{O}$

. . $\dot{3}$. $2 \overline{16}$ i. $\overline{\dot{2}} \cdot \overline{\dot{1}} \overline{\dot{2}} \overline{i 2} . \dot{165.3}$ :]

Pola Tengah Notasi

Sekar Gadung, Lcr. Sl. Myr

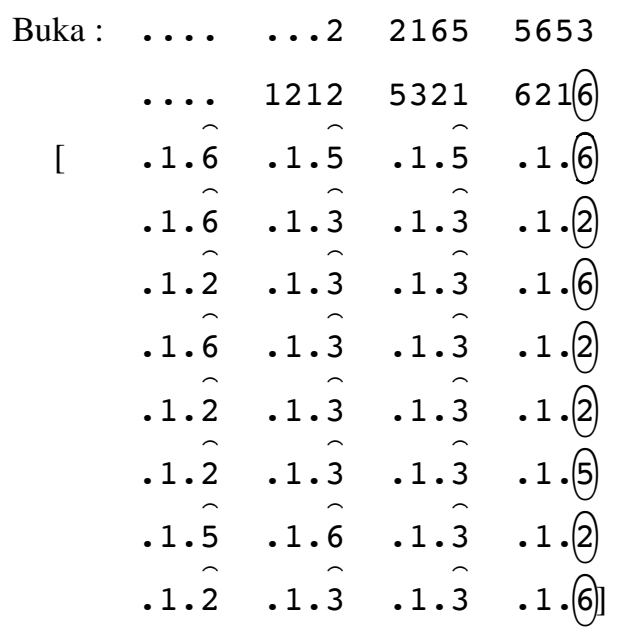

Lobong Ilang, Sl. Myr

Buka : 2

\begin{tabular}{|c|c|c|c|c|}
\hline & 2321 & 3265 & 3353 & 1216 \\
\hline & .352 & .356 & $33 \ldots$ & 1216 \\
\hline & .352 & .356 & $22 \ldots$ & 1312 \\
\hline & $1 / 4$ & 5321 & 3265 & 3516 \\
\hline & {$[33 \ldots$} & 1216 & 3632 & 5316 \\
\hline & $22 \ldots$ & 5321 & 3265 & 10 \\
\hline & han ke c. & & 3353 & 1216 \\
\hline & .352 & .356 & $33 \ldots$ & 1216 \\
\hline & .352 & .356 & $22 \ldots$ & 2 \\
\hline
\end{tabular}




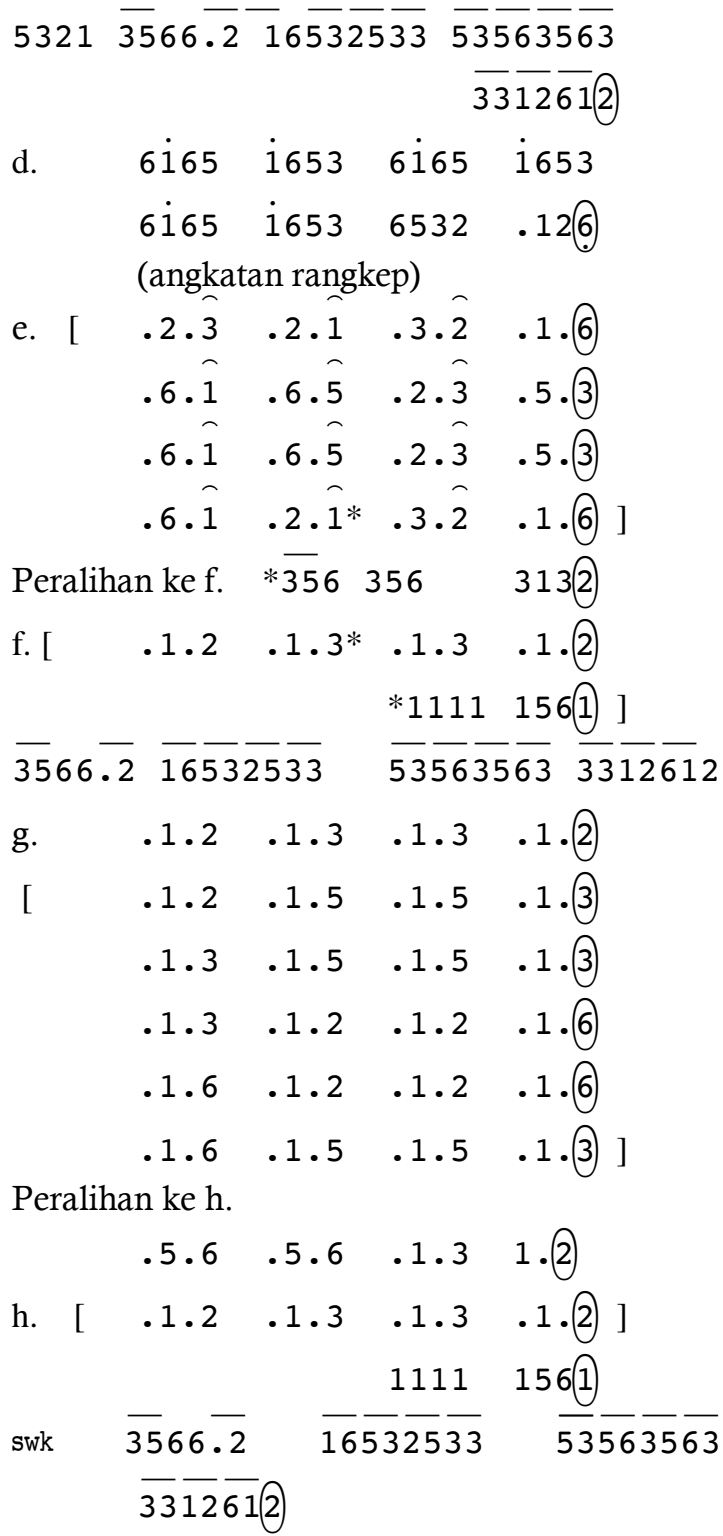

Gerong Lobong Ilang (Salisir)

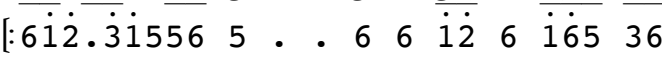
wa-lu-lu wing Pa-ra-be sang sma-ra ba-ngun Du-wa-lu-lu wing Gar-wa sang si ndu-ra pra -bu $\mathrm{Du}-$

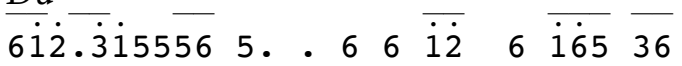
wa-lu-lu wing Se-pat dom- $\bar{b}$ a ka-li a-ya Duwa-lu-lu wing Wi- ca- ra- ma wa ka- ra- na $\mathrm{Du}-$

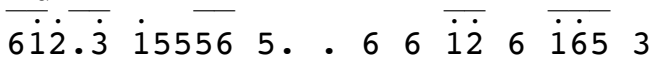
wa-lu-lu wing A-ja do-lan lan wong pri- ya wa-lu-luwing A- ja do- lan lan wa-nita $\begin{array}{lllllllllll}\ldots \overline{3} & \overline{35} & \overline{65} & \overline{32} & \overline{1.3} & \overline{356} & \overline{56} & \overline{.2} & 1 & \overline{21} & 6\end{array}$
A-ja do-lan lan wong priya Gu-ra meh no ra pra-sa----ja

Tan-nyata a-sring kre-tar-ta Ngana ngene pada bae

Pola Akhir Notasi

Lancaran eling-eling S1. Manyura

\begin{tabular}{|c|c|c|c|}
\hline Buka: & $\ldots 6 \quad 6563$ & 2523 & 5616 \\
\hline$[\because .1 .6$ & .1 .5 & .1 .5 & .1 .6 \\
\hline .1 .6 & .1 .5 & .1 .5 & .1 .6 \\
\hline .3 .2 & $.3 . \hat{2}$ & .3 .5 & .6 .5 \\
\hline .6 .5 & .3 .2 & .3 .5 & .1 .6 \\
\hline
\end{tabular}

\section{Tempat pertunjukan}

Tora Dinata menuturkan bahwa tempat pementasan lengger lanang langgeng sari biasanya disajikan diruang terbuka seperti halaman rumah, lapangan dan alun-alun, juga di pentaskan di dalam ruangan seperti di pendapa, gedung, dan hotel. Tempat ini di sediakan jika kesenian ini pentas dalam serangkaian acara perlombaan, resepsi pernikahan yang sekarang ini sering di laksanakan di dalam gedung, dan hotel berbintang. Tetapi tidak menutup kemungkinan jika kesenian lengger masih dipentaskan di halaman, lapangan, alun-alun maupun tempat terbuka yang lainnya yang di sesuaikan dengan permintaan dan kebutuhan penyelenggara. (Wawancara 20 Desember 2018)

\section{Fenomena Penari Cross Gender Dalam Perunjukan Lengger}

Fenomena penari cross gender dalam pertunjukan Lengger dapat ditunjukan dari segi gerak, penari cross gender menari dengan gerakan perempuan yang memiliki volume gerak yang keci, luwes, lincah, dan terkesan erotis sebagaimana mestinya seorang penari Lengger dalam sebuah pertunjukan Lengger seperti yang dijukan pada gambar no 3 .

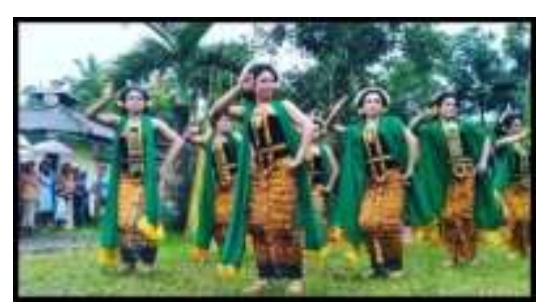

Gambar 3. Fenomena Pertunjukan Lengger (Foto: Paguyuban Rumah Lengger Lanang Langgeng Sari, 2018) 
Penari cross gender juga sering menggunakan gerakan laki-laki atau putra gagah dengan tenaga yang kuat, dalam beberapa pertunjukan Lengger, yang menggunakan properti ebeg, untuk menujukan bahwa jati diri mereka adalah sebagai seroang laki-laki.

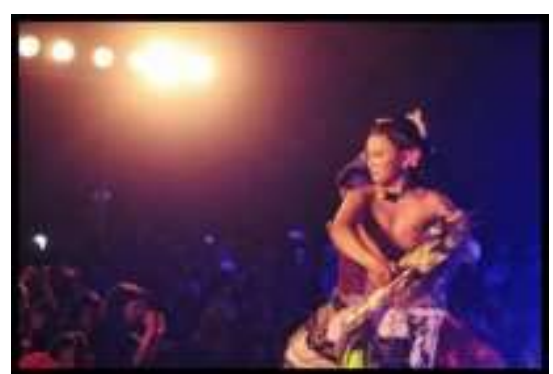

Gambar 4. Gerak Putra Menggunakan Ebeg (Foto : Paguyuban Rumah Lengger Lanang Langgeng Sari, 2018)

Fenomena penari cross gender dalam pertunjukan Lengger juga dapat dilihat dari segi rias busana. Untuk menyiasati wajah penari laki-laki agar menyerupai wajah seorang perempuan, penari Lengger menggunakan tata rias korektif dalam setiap pertunjukan Lengger. Tata rias korektif ini bertujuan untuk menyembunyikan kekurangan-kekurangan yang ada pada wajah dan menonjolkan hal-hal yang menarik dari wajah penari Lengger Lanang Langgeng Sari yang dapat memeberikan kesan cantik.

Penari Lengger Paguyuban Rumah Lengger memiliki rambut yang pendek seperti halnya seorang laki-laki pada umumnya, untuk menyiasati hal tersebut penari Lengger menggunakan sanggul pasangan yang dibuat sendiri oleh penari, sanggul yang digunakan antara subal dan konde sudah dijahit menjadi satu, agar penari lebih mudah memakainya, cara memakai sanggul sama seperti memakai topi pada umumnya, setelah sanggul dipasang penari lengger menambahkan hiasan sanggul seperti srikam, mentul, gunungan, dan hiasan bunga.

Busana yang digunakan penari Lengger meliputu mekak, ilat-ilatan, sabuk timang, jarit duyung. Sebelum memaki jarit penari lengger menggunakan bokongan. Bokongan merupakan sejenis bantal berbentuk bulat yang dipakai pada bagian bokong penari sebelum memakai jarit, yang bertujuanuntuk membentuk bagian bokong agar lebih menonjol layaknya seorang perempuan ketika menggunakan kain jarit. Pada bagian dada penari agar terlihat seperti perempuan, mereka menggunakan streples yang di dalamnya diisi dengan spons agar dada penari terlihat seperti dada perempuan, sebelum mereka menggunakan mekak.

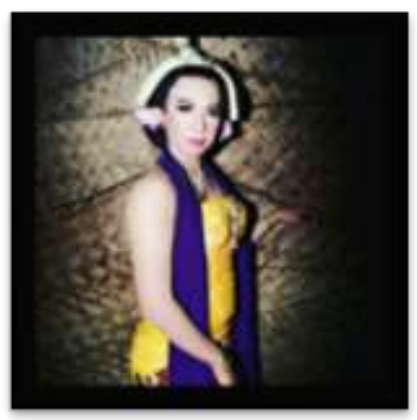

Gambar 5. Rias Busana Pertunjukan Lengger (Foto: Paguyuban Rumah Lengger Lanang Langgeng Sari, 2019)

\section{SIMPULAN}

Hasil penelitian, dapat disimpulkan bahwa fenomena bentuk pertunjukan dari Kesenian Lengger Paguyuban Rumah Lengger atau yang lebih dikenal dengan nama Lengger Lanang Langgeng Sari yang ada di Desa Pandak kecamatan Baturaden Kabupaten Banyumas, terdapat elemen-elemen yang mendasari pertunjukan kesenian lengger yang terdiri dari struktur pertunjukan (yang meliputi pola awal, pola tengah, dan pola akhir pertunjukan), properti, gerak, tata rias dan tata busana, musik iringan, dan tempat pertunjukan.

Saran yang dapat diberikan oleh peneliti untuk pelaku pertunjukan Lengger Paguyuban Rumah Lengger adalah penari Lengger Paguyuban Rumah Lengger diharapkan akan terus berlatih dengan rutin lagi mengenai teknik dasar gerak lenggeran untuk meningkatkankualitas gerak saat menari. Penari Lengger Paguyuban Rumah Lengger diharapkan dapat menjaga kekompakan setiap anggota penari agar kesenian Lengger Paguyuban Rumah Lengger tetap lestari. Yang kedua adalah Paguyuban Rumah Lengger sebagai salah satu paguyuban lengger yang berada di Kabupaten Banyumas diharapkan dapat terus mengembangkan karya seni dengan melestarikan potensi kesenian daerah yang ada didalamnya. Dalam kegiatan yang telah dijalankan agar tetap dijaga kelestariannya untuk lebih menarik lagi agar memunculkan bibit-bibit generasi penerus selanjutnya untuk mengikuti latihan menari. 


\section{DAFTAR PUSTAKA}

Bandem, I. M. 1996. Etnologi Tari Bali. Yogyakarta: Kaninsius.

Bisri, H. 2010. "Bias Gender Koreografi Wanita Dalam Karya Tari". Harmonia , X No 2 2010.

Budiarti, M. 2003. "Mengubah Citra Lengger Menjadi Media Ekspresi Estetis". Harmonia Jurnal Pengetahuan Dan Pemikiran Seni, VOL. IV No. 22/Mei Agustus 2003.

Creswell, J.W. 2013. Research Design Pendekatan Kualitatif, Kuantitatif, Dan Mixed. Yogyakarta: Pustaka Pelajar.

Djelantik, A. 1999. Estetika Sebuah Pengantar. Bandung: Masyarakat Seni Pertunjukan Indonesia.

Edi, S. 1986. Pengetahuan Elemen Tari. Jakarta: Proyek Pengembangan Kesenian.

Hartono. 2017. Apresiasi Seni Tari. Semarang: Fakultas Bahasa Dan Seni Universitas Negeri Semarang.

Hadi, S. 2005. Sosiologi Tari. Yogyakarta: Pustaka.

Hidayat, R. 2005. Wawasan Seni Tari. Malang: Unit Pengembangan Profesi Tari.

Jazuli, M. 2016. Peta Dunia Seni Tari. Sukoharjo: CV. Farishma Indonesia.

Lutfiana, D. 2017. "Estetika Bentuk Pertunjukan Tari Lenggang Pari Di Sanggar Seni Perwitasari Kelurahan Kemandungan Kecamatan Tegal Barat Kota Tegal". Skripsi. Universitas Negeri Semarang: Semarang.

Moleong, L. 2001. Metodologi Penelitian Kualitatif. Bandung: Pt Remaja Rosdakarya.

Rochman , M. M. 2015. "Fenomena CrossGender Dalam Raminten 3 Cabaret Show, Mirota Batik", Yogyakarta. Jurnal Pendidikan Sosiologi .

Sunaryadi. 2000. Memahami Penelitian Kualitatif. Yogyakarta: Yayasan Untuk Indonesia.

Sutiyono. 2009. Puspawarna Seni Tradisi. Yogyakarta: Kanwa Ublisher.

Thowok, D. N. 2005. Cross Gender Didik Nini Thowok. Malang: Sava Media.

Widyastutieningrum, S. R. 2012. Revitalisasi Tari Gaya Surakarta. Surakarta: ISI Press. 